SAMMLUNG TUSCULUM

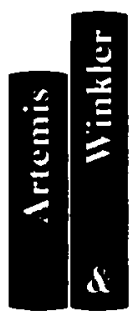


Sammlung Tusculum

Herausgegeben von

Karl Bayer, Manfred Fuhrmann,

Gerhard Jäger 
MARCUS TULLIUS CICERO

\section{DER STAAT}

Lateinisch und Deutsch

Herausgegeben und übersetzt von Karl Büchner

ARTEMIS \& WINKLER VERLAG 
Der Verlag dankt Peter L. Schmidt für die Zusammenstellung der Bibliographie.

Die Deutsche Bibliothek - CIP-Einheitsaufnahme

Cicero, Marcus Tullius:

Der Staat: lat. u. dt.; Marcus Tullius Cicero.

Hrsg. und übers, von Karl Büchner.

5. Auf. - München; Zürich: Artemis und Winkler, 1993

(Sammlung Tusculum)

Einheitssacht.: De re publica

ISBN 3-7608-1653-3

NE: Büchner, Karl [Hrsg.]

5. Auflage 1993

Artemis \& Winkler Verlag

C 1993 Artemis Verlags GmbH, München.

Alle Rechte, einschlieBlich derjenigen des auszugsweisen Abdrucks und der photomechanischen Wiedergabe, vorbehalten.

Druck: Bosch-Druck, Landshut.

Printed in Germany 